\title{
Geochemical Characterization of Two Niger Delta Crude Oils and Their Mixtures II: Correlation of Bulk Properties and Aliphatic Hydrocarbons
}

\author{
Mark Obinna Onyema*, Nwannedi Christian Okoroh, Ikenna Hope Okorie, Leo Chigbu Osuji \\ Department of Pure and Industrial Chemistry, University of Port Harcourt, Port Harcourt, Nigeria \\ Email address: \\ onyemark@yahoo.com (M. O. Onyema) \\ *Corresponding author \\ To cite this article: \\ Mark O. Onyema, Nwannedi C. Okoroh, Ikenna H. Okorie, Leo C. Osuji. Geochemical Characterization of Two Niger Delta Crude Oils and \\ Their Mixtures II: Correlation of Bulk Properties and Aliphatic Hydrocarbons. Science Journal of Chemistry. Vol. 8, No. 5, 2020 , pp. 107-112. \\ doi: $10.11648 /$ j.sjc. 20200805.12
}

Received: November 29, 2019; Accepted: December 19, 2019; Published: September 24, 2020

\begin{abstract}
Correlations of bulk geochemical properties such as density, API gravity, saturates, aromatics, resins and asphaltenes (SARA) compositions, aliphatic hydrocarbons (from $n \mathrm{C}_{8}$ to $n \mathrm{C}_{38}$ ) and their diagnostic ratios $\left(\mathrm{Pr} / \mathrm{Ph}, \operatorname{Pr} / n \mathrm{C}_{17}\right.$ and $\mathrm{Ph} / n \mathrm{C}_{18}$ ) were evaluated for two Niger Delta crude oils (samples A and F) and their mix at different proportions of 4:1, 3:2, 2:3 and 1: 4 (samples B, C, D and E respectively). Pearson correlation showed strong relationships $(>0.99)$ between sample pairs in their bulk geochemical properties and diagnostic ratios, but variable relationships $(0.20-0.85)$ in the aliphatic hydrocarbons which increased with increase in the proportion of sample F. Assessment of aliphatic hydrocarbon compositions by hierarchical cluster analysis (HCA) showed two major groups of clearly differentiated clusters with negative similarity and their plots revealed the aliphatic hydrocarbon compositions increased/decreased from samples $\mathrm{A}$ to $\mathrm{F}$ and exhibited variable strength for correlation of the oil samples. Plots of ratios of the aliphatic hydrocarbons were used to depict the geochemical compositional variations of the oil samples. Coefficient of determination $\left(R^{2}\right)$ of the plots indicate the ratios $\mathrm{C}_{14} / \mathrm{C}_{14}+\mathrm{C}_{25}, \mathrm{C}_{15} / \mathrm{C}_{15}+\mathrm{C}_{24}$ and $\mathrm{C}_{17} / \mathrm{C}_{17}+\mathrm{C}_{23}$ fits well and could account for $99.4 \%, 99.3 \%$ and $99.2 \%$ of the geochemical compositional variations of the two Niger Delta crude oils and their proportional mix. The results suggest these aliphatic hydrocarbon ratios could be useful for estimating the composition of two Niger Delta crude oils in their mix.
\end{abstract}

Keywords: Correlation, Composition, Aliphatic Hydrocarbons, Crude oil Mix, Ratio, Niger Delta

\section{Introduction}

Crude oil is a naturally occurring liquid mixture of hydrocarbon compounds. It is derived from the chemical and geological transformation of organic matter in the depositional environment under the influence of heat and pressure changes over geological time scale $[1,2]$. These conditions transmit a unique geochemical fingerprint to crude oil, which varies from one field to another. Geochemists have used various parameters for crude oil correlation studies. Within the geochemical parameters are embodied essential information on the fate of these crude oils [3]. Part of the parameters so far used include: bulk properties such as density, viscosity, American petroleum institute (API) gravity, percentages of nitrogen-, and sulphur-bearing compounds, compositions of saturates, aromatics, resins and asphaltenes (SARA) and gas chromatography fingerprints of aliphatic hydrocarbons (AHCs), biomarker terpanes and steranes and alkylated polycyclic aromatic hydrocarbons [4-7].

Bulk parameters, such as API gravity, sulphur and nitrogen composition (\%) and SARA are used as indicators of thermal maturity. During thermal maturity, the heavy components in crude oils undergo increased cracking resulting to increase in the composition of the low molecular weight saturated hydrocarbons, API gravity and saturate/aromatic ratio. Sulphur loss occurs early in catagenesis, the second transformation phase of organic matter to crude oil, while nitrogen loss occurs in the late catagenesis or metagenesis (third) phase [8]. Sulphur composition is also an indicator of anaerobic sulphate reduction of organic matter deposited in an 
anoxic environment [9].

Aliphatic hydrocarbon fingerprints (distribution and composition) of crude oils from different sources are characteristic. Ratios of aliphatic hydrocarbons such as pristane/n-heptadecane $(\mathrm{Pr} / \mathrm{nC} 17)$, phytane/n-octadecane $(\mathrm{Ph} / \mathrm{nC} 18)$ pristane/phytane $(\mathrm{Pr} / \mathrm{Ph})$ and carbon preference index (CPI), are commonly used as diagnostic tool for oil correlations and for interpreting geochemical data [10]. They provide valuable information on organic matter source (marine or terrestrial), depositional environment (oxic and anoxic), lithology of the source rock and maturity [11]. These geochemical parameters form the basis for genetic oil-oil and oil-source rock correlations, prediction of oil quality in reservoirs, assessment of reservoir continuity and determination of proportions of commingled production from multiple zones $[12,13]$. Consequently, crude oil correlations require geochemical parameters that unambiguously characterize and discriminate between oil samples on the assumption that the same conditions produce the same oil [14] In this study, correlation of bulk properties, aliphatic hydrocarbons and diagnostic ratios of two Niger Delta crude oils and their mix at different proportions were determined. This could have important implications by identifying geochemical parameters for estimating the composition of two commingled Niger Delta crude oils.

\section{Materials and Methods}

\subsection{Study Area}

Nigeria's Niger Delta region is an extremely prolific hydrocarbon province situated between longitude $5^{\circ}-9^{\circ} \mathrm{E}$ and latitude $4^{\circ}-6^{\circ} \mathrm{N}$ along the West African continental margin. The lithostratigraphic units of the Niger Delta comprises of the marine shale Akata formation, which is overlaid by interbedded marine shale and paralic sands of the Agbada formation and at the top, coastal plain sand sequence of the Benin formation [15].

\subsection{Sampling}

Two crude oils (one litre each) were obtained from Rivers State and Delta State both in the Niger Delta region of Nigeria, with the assistance of officials from the department of petroleum resources (DPR) and used for the study. The crude oils were labelled samples A and F respectively. Mixtures of the two oils were made at different proportions of 4:1, 3:2, 2:3 and $1: 4$ to give samples B, C, D and E respectively.

\subsection{Crude Oil Characterization}

The APAAR density meter DMA 048 was used for determined of the densities and API gravities of the crude oil samples. $50 \mathrm{mg}$ of each crude oil sample was weighed into labelled centrifuge tubes and excess pentane added. The mixture was allowed to stand for four hours to precipitate the asphaltenes and the content filtered out, concentrated and introduced onto the top of a glass chromatographic column $(25 \mathrm{~cm} \times 1 \mathrm{~cm})$ packed with silica gel at the bottom. $n$-Hexane was poured into the packed column to elute the saturates, dichloromethane poured to elute the aromatics and dichloromethane/methanol (1: 1) mixture poured to elute the resins. The eluents were collected into pre-weighed vials and the solvents evaporated to dryness under a gentle stream of nitrogen at $40^{\circ} \mathrm{C}$. The weights of saturates, aromatics, resins and asphaltenes were determined and the normalized percent reported.

\subsection{Gas Chromatography Analysis}

Agilent's gas chromatography (GC) system 7890B equipped with an HP-5 silica capillary column $30 \mathrm{~m}$ x $320 \mu \mathrm{m}$ ID and $0.25 \mu \mathrm{m}$ film thickness and fitted with a flame ionization detector (FID) was used for aliphatic hydrocarbon analysis. One microlitre $(1 \mu \mathrm{L})$ of the saturate fraction from column chromatography was injected into the GC capillary column with the aid of a G4513A automatic liquid sampler. Oven temperature programme was a $5 \mathrm{~min}$ hold at $40^{\circ} \mathrm{C}$, from 40 to $315^{\circ} \mathrm{C}$ at $5^{\circ} \mathrm{C} / \mathrm{min}$ and $30 \mathrm{~min}$ hold at $315^{\circ} \mathrm{C}$. Quantification was by area integration of each identified peak and processed by Chemstation OPEN LAB CDS software.

\subsection{Statistical Analysis}

Statistical analyses were performed with Microsoft Excel 2007 and PAST 3.22 [16].

\section{Results and Discussion}

\subsection{Correlation of the Crude Oil Samples}

Results of density, API gravity, compositions of SARA and aliphatic hydrocarbons as well as commonly used diagnostic ratios $\left(\mathrm{Pr} / \mathrm{Ph}, \mathrm{Pr} / \mathrm{C}_{17}\right.$ and $\left.\mathrm{Ph} / \mathrm{C}_{18}\right)$ of the two Niger Delta crude oils (samples A and F) and their proportional mix (samples B, C, D, and E) are presented in Onyema et al. [17]. Relationships between crude oil sample pairs were evaluated using Pearson's correlation. Pearson correlation $(r)$ is commonly used in statistics to show the strength of a linear relationship between two sets of data. The correlation values range between -1 and 1 , which indicate a strong negative or positive relationship respectively, while a value of zero indicates that the two sets of data show no relationship. Results of Pearson correlation of the crude oil samples for bulk geochemical properties and diagnostic ratios is presented in table 1 and for the distribution of aliphatic hydrocarbons $\left(\mathrm{C}_{8}\right.$ $-\mathrm{C}_{38}$ ) is presented in table 2 .

Table 1 shows a strong positive correlation of 0.99447 between samples $\mathrm{A}$ and $\mathrm{F}$ in their bulk properties and diagnostic ratios. From the Pearson correlation result, the two Niger Delta crude oils from Rivers and Delta states, samples A and $\mathrm{F}$, are significantly similar in bulk properties and diagnostic ratios, indicating that these oils are genetically related [18, 19]. Geochemical fingerprinting of the Niger Delta crude oils on the basis of the aliphatic hydrocarbon diagnostic ratios, biomarkers and oleanane content suggest a mainly terrestrial and mixed marine and terrestrial organic matter derived oils [20, 21]. Samples B, C, D, and E also show 
a strong correlation $(>0.99)$ with each other in their bulk properties and diagnostic ratios (Table 1). The strong correlation indicates that all the oil samples (A - F) were significantly similar in their bulk properties and aliphatic hydrocarbon diagnostic ratios to permit meaningful differentiation of the two Niger Delta crude oils and their proportional mix.

Table 1. Pearson correlation (r) of two Niger Delta crude oils and their proportional mix for bulk geochemical properties and aliphatic hydrocarbon diagnostic ratios.

\begin{tabular}{llllll}
\hline & Sample A & Sample B & Sample C & Sample D & Sample E \\
\hline Sample A & & & & & \\
Sample B & 0.9999 & & & & \\
Sample C & 0.99975 & 0.99993 & 0.9999 & & \\
Sample D & 0.99933 & 0.99969 & 0.99858 & 0.99912 & 0.99723 \\
Sample E & 0.99725 & 0.99793 & 0.99624 & 0.99723 \\
Sample F & 0.99447 & 0.99572 & & \\
\hline
\end{tabular}

Table 2. Pearson correlation ( $r$ ) of two Niger Delta crude oils and their proportional mix for aliphatic hydrocarbon $\left(C_{8}-C_{38}\right)$ distributions.

\begin{tabular}{llllll}
\hline & Sample A & Sample B & Sample C & Sample D & Sample E \\
\hline Sample A & & & & & \\
Sample B & 0.92966 & & & \\
Sample C & 0.44562 & 0.42736 & 0.84988 & & \\
Sample D & 0.55524 & 0.58837 & 0.87335 & 0.95383 & 0.84126 \\
Sample E & 0.41778 & 0.49278 & 0.81292 & 0.85246 & 0.21354 \\
Sample F & 0.20456 & 0.2136 & \\
\hline
\end{tabular}

Table 2 shows a variable correlation between sample pairs in their aliphatic hydrocarbons. Samples A and F show weak correlation (0.20456) which indicate difference in the aliphatic hydrocarbon distributions of the two Niger Delta crude oils. Samples B, C, D, and E, show variable correlations which indicate differences in the aliphatic hydrocarbon distributions of the oil samples (table 2). Their correlation was observed to increase with an increase in the proportion of sample F. For example, the correlation between samples B, C, $\mathrm{D}$, and $\mathrm{E}$ with $\mathrm{F}$ was $0.21,0.81,0.85$ and 0.84 respectively. The variable correlations indicate differences in the aliphatic hydrocarbon distributions of the oil samples. Barakat et al. (1997) showed the geochemical characteristics of five crude oils from the Gulf of Suez vary sufficiently to suggest multiple sources [22]. From table 2, the variable correlations observed indicate that all the oil samples (A - F) showed differences in their aliphatic hydrocarbon distributions to permit meaningful differentiation of the two Niger Delta crude oils and their proportional mix.

\subsection{Multivariate Correlation}

Hierarchical cluster analysis (HCA) is a multivariate correlative tool that determines similarities among individual elements with which it uses to build a hierarchy of clusters [23]. HCA was utilized for multivariate data analysis of the variable distributions of the aliphatic hydrocarbons among the oil samples. For individual and commingled Niger Delta crude oils, Okoroh et al. (2018) observed the relative composition of hydrocarbons correlated more than their area [24]. HCA was applied to the aliphatic hydrocarbon compositions of the oil samples and the result presented in figure 1 .

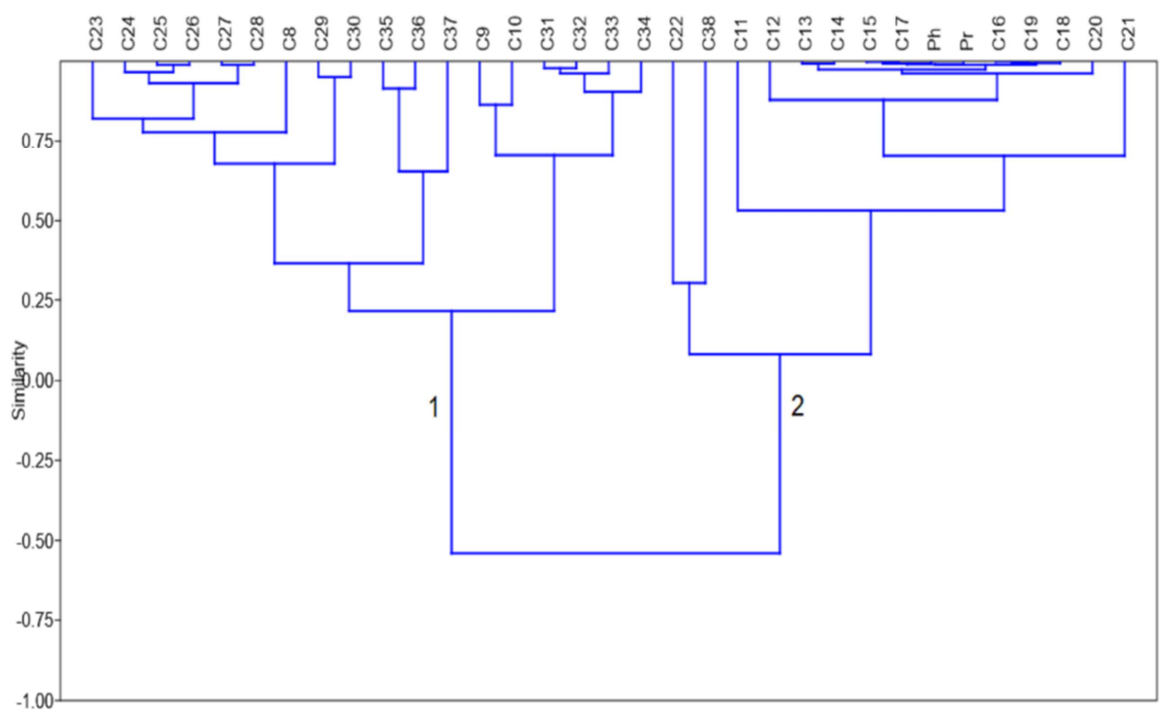

Figure 1. Hierarchical cluster analysis (HCA) dendogram showing the relationship among the compositions of aliphatic hydrocarbons $\left(C_{8}-C_{38}\right)$ in the crude oil samples. 
From figure 1, HCA separated the aliphatic hydrocarbons, based on compositions, into two major groups. Group 1 comprised of 18 aliphatic hydrocarbons, which include $\mathrm{C}_{8}$, $\mathrm{C}_{9}, \mathrm{C}_{10}, \mathrm{C}_{23}, \mathrm{C}_{24}, \mathrm{C}_{25}, \mathrm{C}_{26}, \mathrm{C}_{27}, \mathrm{C}_{28}, \mathrm{C}_{29}, \mathrm{C}_{30}, \mathrm{C}_{31}, \mathrm{C}_{32}, \mathrm{C}_{33}$, $\mathrm{C}_{34}, \mathrm{C}_{35}, \mathrm{C}_{36}$ and $\mathrm{C}_{37}$, and group 2 comprised of 15 which include $\mathrm{C}_{11}, \mathrm{C}_{12}, \mathrm{C}_{13}, \mathrm{C}_{14}, \mathrm{C}_{15}, \mathrm{C}_{16}, \mathrm{Pr}, \mathrm{C}_{17}, \mathrm{Ph}, \mathrm{C}_{18}, \mathrm{C}_{19}, \mathrm{C}_{20}$, $\mathrm{C}_{21}, \mathrm{C}_{22}$ and $\mathrm{C}_{38}$ (figure 1). The two groups of aliphatic hydrocarbons showed negative similarity on the HCA dendrogram. This result revealed the compositions of the aliphatic hydrocarbons in the crude oil samples distinctly differed in their variations. Composition of some aliphatic hydrocarbons from group $1\left(\mathrm{C}_{23}, \mathrm{C}_{24}, \mathrm{C}_{27}, \mathrm{C}_{28}, \mathrm{C}_{29}\right.$, and $\left.\mathrm{C}_{36}\right)$ and group $2\left(\mathrm{C}_{11}, \mathrm{C}_{12}, \mathrm{C}_{14}, \mathrm{C}_{15}, \mathrm{Pr}\right.$, and $\left.\mathrm{C}_{22}\right)$ were plotted against the crude oil samples and shown in figures 2 - 3 respectively.

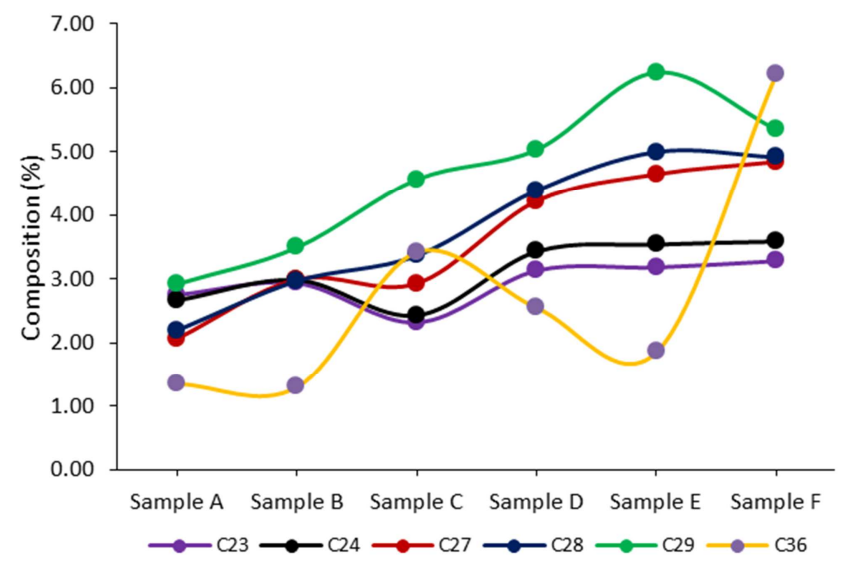

Figure 2. Plot of the composition of some group 1 aliphatic hydrocarbons $\left(C_{23}, C_{24}, C_{27}, C_{28}, C_{29}\right.$, and $\left.C_{36}\right)$ against the crude oil samples.

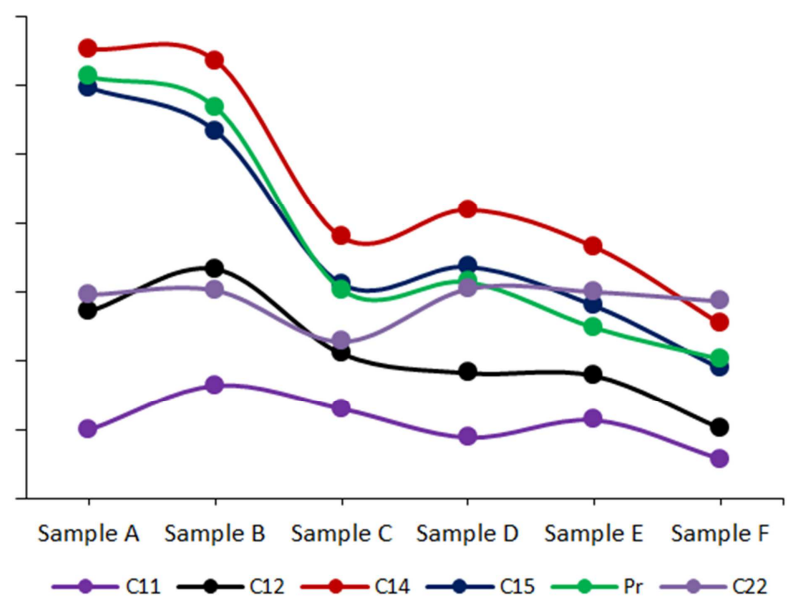

Figure 3. Plot of the composition of some group 2 aliphatic hydrocarbons $\left(C_{11}\right.$, $C_{12}, C_{14}, C_{15}, P r$, and $C_{22}$ ) against the crude oil samples.

Figures 2 and 3 show correlation of the aliphatic hydrocarbon compositions in the crude oil samples. Plots of $\mathrm{C}_{23}, \mathrm{C}_{24}, \mathrm{C}_{27}, \mathrm{C}_{28}, \mathrm{C}_{29}$ and $\mathrm{C}_{36}$ (group 1) showed the increasing composition values from samples $\mathrm{A}$ to $\mathrm{F}$ (positive slopes), while plots of $\mathrm{C}_{11}, \mathrm{C}_{12}, \mathrm{C}_{14}, \mathrm{C}_{15}, \mathrm{Pr}$, and $\mathrm{C}_{22}$ (group 2) showed decreasing composition values from samples A to $\mathrm{F}$ (negative slopes). These plots reveal aliphatic hydrocarbons in group 1 increased with increase in the proportion of sample F, whereas group 2 decreased with an increase in the proportion of sample F. The plots also reveal the strength of the correlation among aliphatic hydrocarbon compositions in the crude oil samples. For group 1 aliphatic hydrocarbons (figure 2), the slopes for $\mathrm{C}_{28}$ and $\mathrm{C}_{29}$ with values of 0.59 and 0.60 were higher than for $\mathrm{C}_{23}$ and $\mathrm{C}_{24}$ with values of 0.12 and 0.20 respectively. While for group 2 (figure 3), the slopes for $\mathrm{C}_{14}$ and $\mathrm{Pr}$ with values of -0.79 and -0.86 were higher than for $C_{11}$ and $C_{12}$ with values of -0.11 and -0.38 respectively.

\subsection{Geochemical Plots}

Ratios of aliphatic hydrocarbons that emphasize the composition of the two Niger Delta crude oils in their proportional mix were calculated. The ratios consist of compounds whose aliphatic hydrocarbons whose compositions are most variant as numerators and least variant as denominator [25].



Figure 4. Plot of $C_{14} / C_{14}+C_{25}$ showing the variation of the ratio in the two Niger Delta crude oils and their proportional mix.

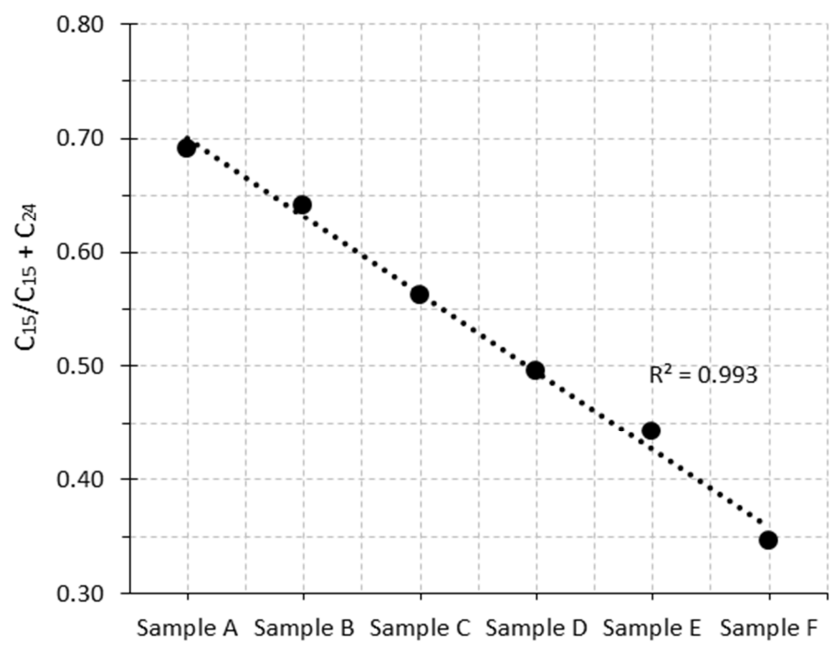

Figure 5. Plot of $C_{15} / C_{15}+C_{24}$ showing the variation of the ratio in the two Niger Delta crude oils and their proportional mix. 


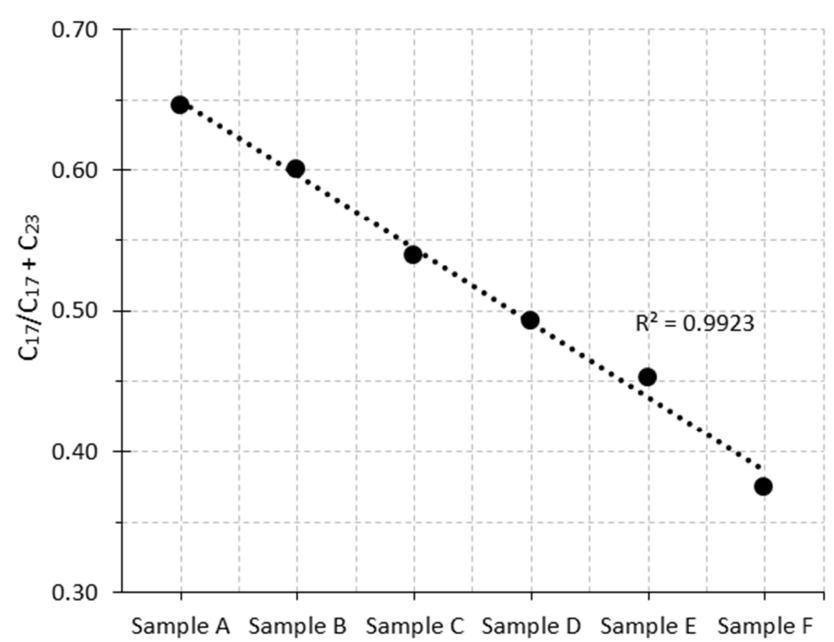

Figure 6. Plot of $C_{17} / C_{17}+C_{23}$ showing the variation of the ratio in the two Niger Delta crude oils and their proportional mix.

Plots of $\mathrm{C}_{14} / \mathrm{C}_{14}+\mathrm{C}_{25}, \mathrm{C}_{15} / \mathrm{C}_{15}+\mathrm{C}_{24}$ and $\mathrm{C}_{17} / \mathrm{C}_{17}+\mathrm{C}_{23}$ ratios depict the geochemical composition variations of the crude oil samples which permit meaningful differentiation (figures 4 - 6). From the plots, the coefficient of determination $\left(\mathrm{R}^{2}\right)$ was $0.9937,0.993$ and 0.9923 respectively. $\mathrm{R}^{2}$ gives information about the goodness of fit of a model and measures how well the predictions estimate the real data points. The $\mathrm{R}^{2}$ value for the plots indicate the aliphatic hydrocarbon ratios $\mathrm{C}_{14} / \mathrm{C}_{14}+\mathrm{C}_{25}, \mathrm{C}_{15} / \mathrm{C}_{15}+\mathrm{C}_{24}$ and $\mathrm{C}_{17} / \mathrm{C}_{17}+\mathrm{C}_{23}$ fits well and could account for $99.4 \%, 99.3 \%$ and $99.2 \%$ of sample data respectively. The results indicate plots of these aliphatic hydrocarbon ratios, calculated from the chromatographic peaks could be useful for estimating the composition of the two Niger Delta crude oils, in their proportional mix.

\section{Conclusion}

Pearson correlation of the of two Niger Delta crude oils and their mix at different proportions showed strong correlation for bulk geochemical properties (density, API gravity, saturates, aromatics, resins, asphaltenes) and diagnostic ratios $\left(\mathrm{Pr} / \mathrm{Ph}, \mathrm{Pr} / \mathrm{C}_{17}\right.$ and $\left.\mathrm{Ph} / \mathrm{C}_{18}\right)$, but variable correlations for the aliphatic hydrocarbon distributions. Multivariate correlation revealed the aliphatic hydrocarbons exhibited variable strength for correlation of the oil samples and two types of variation in their compositions (increase/decrease). Plots of ratios of aliphatic hydrocarbons with a strong correlation $\left(\mathrm{C}_{14} / \mathrm{C}_{14}+\right.$ $\mathrm{C}_{25}, \mathrm{C}_{15} / \mathrm{C}_{15}+\mathrm{C}_{24}$ and $\mathrm{C}_{17} / \mathrm{C}_{17}+\mathrm{C}_{23}$ ) depict the chemical composition variations between the two Niger Delta crude oils and their mix. Coefficient of determination $\left(\mathrm{R}^{2}\right)$ values from the plots were considerably high and could account for $99.4 \%, 99.3 \%$ and $99.2 \%$ of sample data respectively. Consequently, the relative composition (ratios) of these aliphatic hydrocarbons could be used for estimation of the composition of two Niger Delta crude oils in their mix at different proportions.

\section{References}

[1] J. M. Hunt, "Petroleum geochemistry and geology", 2nd Edition, W. H. Freeman and Company, U. S. A., 1996, pp. 1-743.

[2] R. P. Philp, "Formation and geochemistry of oil and gas", Treatise on geochemistry (Second Edition), 2014, vol. 9, pp. 233-265.

[3] L. C. Osuji and B. S. Antia, "Geochemical implication of some chemical fossils as indicators of petroleum source rocks", Journal of Applied Science and Environmental Management, 2005, vol. 9 (1), pp. 45-49.

[4] M. A. Younes, "Application of biomarkers and stable carbon isotopes to access the depositional environment of source rocks and the maturation of oils, East Zeit field, southern Gulf of Suez Egypt", Petroleum Science and Technology, 2001, vol. 19, pp. 1039-1081.

[5] L. O. Oyekunle and O. A. Famakin, "Studies of Nigerian crudes I. Characterization of crude oil mixtures", Petroleum Science and Technology, 2004, vol. 22, pp. 665-675.

[6] H. Volk, S. C. George, H. Middleton and S. Schofield, "Geochemical comparison of fluid inclusion and present-day oil accumulations in the Papuan Foreland - Evidence for previously unrecognized petroleum source rocks", Organic Geochemistry, 2005, vol. 36, pp. 29-51.

[7] T. K. Al-Ameri, A. K. Al-Temimi, and J. Zumberge, "Assessments of oil characterization, source affinities, and hydrocarbon dynamic of East Baghdad oil fields, Central Iraq", Marine and Petroleum Geology, 2016, vol. 77, pp. 353-375.

[8] B. P. Tissot and D. H. Welte, "Petroleum formation and occurrence. A new approach to oil and gas exploration", Springer-Verlag, New York, 1984, pp. 1-538.

[9] S. C. Kolonic, J. S. Sinninghe Damste, M. E. Bittcher, M. M. M. Kuypers, W. Kuhntd, B. Beckmann, G. Scheeder and T. Wegner, "Geochemical characterization of cenomanian/turonian black shales from the Tarfaya basins (SW Morocco): Relationship between paleoenvironmental conditions and early sulphurization of sedimentary organic matter", Journal of Petroleum Geology, 2002, vol. 25, pp. 325-350.

[10] K. E. Peters, C. C. Walters and J. W. Moldowan, The biomarker guide: Biomarkers and isotopes in petroleum and earth history, 2nd ed, Cambridge University Press, Cambridge, UK, 2005, pp. $1-632$.

[11] G. Shungunam, "Significance of coniferous rain forests and related oils, Gippsland Basin, Australia", American Association Petroleum Geologist Bulletin, 1985, vol. 69, pp. $1241-1254$

[12] K. E. Peters and M. G. Fowler, "Applications of petroleum geochemistry to exploration and reservoir management", Organic Geochemistry, 2002, vol. 33 (1), pp. 5-36.

[13] A. E. Pomerantz, G. T. Ventura, A. M. McKenna, J. A. Cañas, J. Auman, K. Koerner, D. Curry, R. K. Nelson, C. M. Reddy, R. P. Rodgers, A. G. Marshall, K. E. Peters and O. C. Mullins, "Combining biomarker and bulk compositional gradient analysis to assess reservoir connectivity", Organic Geochemistry, 2010, vol. 41 (8), pp. 812-821. 
[14] D. He, D. Hou, T. Chen, "Geochemical characteristics and analysis of crude-oil source in the deep-water area of the Baiyun Sag, South China Sea", Russian Geology and Geophysics, 2018, vol. 59 (5), pp. 499-511.

[15] L. W. M. Tuttle, R. R. Charpentier and E. M. Brownfield, "Chapter A. Tertiary Niger Delta (Akata-Agbada) petroleum system (No. 719201) Niger Delta province, Nigeria, Cameroon, and Equatorial Guinea, Africa", U. S. Geological Survey, World Energy Project Open-File Report, 1999, 99-50-H.

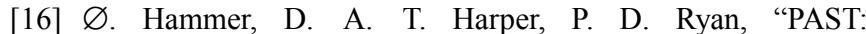
Paleontological statistical software package for education and data analysis", Paleontologia Electronica, 2001, vol. 4 (1), pp. 9.

[17] M. O. Onyema, N. C. Okoroh, I. H. Okorie, and L. C. Osuji, "Geochemical characterization of two niger delta crude oils and their mixtures I: Bulk properties and aliphatic hydrocarbon distributions", Modern Chemistry, 2018, vol. 6 (3), pp. 39-43.

[18] P. N. Manilla and O. M. Onyema, "Correlation of some crude oils using low molecular weight geochemical markers: A case study of the Niger Delta", Journal of Chemical Society of Nigeria, 2008, vol. 33, pp. 225-234.

[19] A. Permanyer, G. MÃ jrquez and J. R. Gallego, "Compositional variability in oils and formation waters from the Ayoluengo and HontomÃn fields (Burgos, Spain)", Implications for assessing biodegradation and reservoir compartmentalization", Organic Geochemistry, 2013, vol. 54, pp. 125-139.
[20] C. M. Ekweozor and T. O. Udo, "The Oleananes: Origin, maturation and limits of occurrence in Southern Nigeria's Sedimentary Basins”, Organic Geochemistry, 1988, vol. 13, pp. 131-140.

[21] C. I. Eneogwe and O. Ekundayo "Geochemical correlation of crude oils in the NW Niger Delta, Nigeria", Journal of Petroleum Geology, 2003, vol. 26, pp. 95-103.

[22] A. O. Barakat, A. Mostafa, M. S. El-Gayar and J. Rullkötter, "Source-dependent biomarker properties of five crude oils from the Gulf of Suez, Egypt", Organic Geochemistry, 1997, vol. 26 (7 and 8), pp. 441-450.

[23] J. L. Pavón, A. G. Peña, C. G. Pinto and B. M. Cordero, "Differentiation of types of crude oils in polluted soil samples by headspace-fast gas chromatography-mass spectrometry", Journal of Chromatography A, 2006, vol. 1137 (1), pp. 101-109.

[24] N. C. Okoroh, M. O. Onyema and L. C. Osuji, "Compositional significance of phenanthrenes for geochemical correlation of two commingled Niger Delta crude oils", Petroleum and Coal, 2018, vol. 60 (6), pp. 1328-1335.

[25] H. I. Halpern, "Development and applications of light-hydrocarbon-based star diagrams", American Association of Petroleum Geologists Bulletin, 1995, vol. 76, pp. 801-815. 